\title{
Surrogate Modeling for Characterizing the Performance of Dielectric Barrier Discharge Plasma Actuator
}

\author{
Young-Chang $\mathrm{Cho}^{* 1}$, Balaji Jayaraman ${ }^{\dagger 2}$, Felipe A. C. Viana ${ }^{\ddagger 3}$, \\ Raphael T. Haftk ${ }^{\S 3}$ and Wei Shyy ${ }^{* * 1}$ \\ ${ }^{I}$ Department of Aerospace Engineering, University of Michigan, Ann Arbor, MI 48109 \\ ${ }^{2}$ T-3 Fluid Dynamics Group, Los Alamos National Laboratory, NM 87545 \\ ${ }^{3}$ Department of Mechanical and Aerospace Engineering, University of Florida, Gainesville, FL 32611
}

\begin{abstract}
The dielectric barrier discharge (DBD) plasma actuator offers promising opportunities for flow control because it does not require mass injection and involves no moving mechanical components. In order to gain better understanding of the impact of the materials and operational parameters on the performance of the DBD actuator, and to facilitate design of effective control schemes, the surrogate modeling technique is adopted. The model is established based on three design variables, namely (i) frequency of the applied voltage, (ii) dielectric constant of the insulator, and (iii) polarity (positive/negative) time ratio of the applied waveform, and focuses on two objectives, namely, (i) net force generated, and (ii) power requirement. The 2 -species fluid plasma model with helium as a working gas is used in the computational model to generate the data needed by the surrogate model. Multiple surrogate models are compared to enhance the robustness of the surrogate performance. There exist multiple Pareto fronts where the $x$-directional force is positive with relatively low power and negative with high power respectively. Global sensitivity analysis indicates that the frequency of the applied voltage is important for the actuator performance in one region whereas the time ratio of the applied waveform is in the other, while the dielectric constant is always important. The performance dependency on variables also differs significantly according to the different regions.
\end{abstract}

D

$\mathrm{d}_{\mathrm{e}}$

E

$\mathrm{F}_{\mathrm{x}}$

$\mathrm{F}_{\mathrm{x}, \mathrm{ST}}$

$\mathrm{h}_{\mathrm{d}}$

$1_{\mathrm{el}}$

$1_{\text {eu }}$

$\mathrm{P}_{\mathrm{T}}$

q

$\mathrm{r}_{\mathrm{f}}$

$\bar{r}$

$\mathrm{r}_{\mathrm{ie}}$

$\mathrm{S}$

$\mathrm{S}_{\mathrm{ie}}$

$\mathrm{T}$

$\mathbf{u}=\left(\mathrm{u}_{\mathrm{x}}, \mathrm{u}_{\mathrm{y}}\right)$

$\mathrm{n}$

\section{Nomenclature}

$=$ Diffusivity of charged particles

$=$ Gap distance between electrodes

$=$ Electric field vector

= Instantaneous $\mathrm{x}$-directional force

$=$ Time and domain averaged $\mathrm{x}$-directional force

$=$ Dielectric material thickness

$=$ Length of lower electrode

$=$ Length of upper electrode

$=$ Power input per one period

$=$ Charge of one species particle

$=$ Positive to negative time ratio of the applied waveform

$=$ Position vector

$=$ Destruction rate of couples of particles

$=$ Area of the computational domain

$=$ Creation rate of couples of particles

$=$ Period of the applied voltage

$=$ Cell-averaged velocity of charged particles

$=$ Particle number density

\footnotetext{
* Graduate Research Assistant, Student Member AIAA

${ }^{\dagger}$ Technical Staff Member (Research Associate), Member AIAA

* Research Scholar

${ }^{\S}$ Distinguished Professor, Fellow AIAA

** Clarence L "Kelly" Johnson Professor, Fellow AIAA
}

American Institute of Aeronautics and Astronautics 


\begin{tabular}{|c|c|}
\hline$V_{\text {app }}$ & $=$ Applied voltage \\
\hline$\varepsilon_{0}$ & $=$ Permittivity of vacuum \\
\hline$\varepsilon_{\text {gas }}$ & $=$ Relative permittivity of gas \\
\hline$\varepsilon_{\mathrm{d}}$ & $=$ Relative permittivity of the dielectric material \\
\hline$\mu$ & $=$ Mobility of charged particles \\
\hline \multicolumn{2}{|c|}{ Subscripts } \\
\hline e & $=$ electron \\
\hline i & $=$ ion \\
\hline $\mathrm{p}$ & $=$ Particle species \\
\hline \multicolumn{2}{|c|}{ Acronyms } \\
\hline BDF & $=$ Backward differentiation formula \\
\hline DB & $=$ Distance-based design \\
\hline DBD & $=$ Dielectric barrier discharge \\
\hline FCCD & $=$ Face-centered composite design \\
\hline GSA & $=$ Global sensitivity analysis \\
\hline GQ & = Gaussian Quadrature \\
\hline KRG & $=$ Kriging model \\
\hline LHS & $=$ Latin-hypercube sampling \\
\hline MS & $=$ Multiple surrogate model \\
\hline PRESS & $=$ Square root of predicted residual sum of squares \\
\hline PRS & $=$ Polynomial response surface model \\
\hline RBNN & $=$ Radial basis neural network model \\
\hline SBO & $=$ Surrogate-based optimization \\
\hline
\end{tabular}

\section{Introduction}

The dielectric-barrier discharge (DBD) plasma actuator is a flow control device that is comprised of two asymmetrically placed electrodes separated by a dielectric barrier (insulator) and driven by the kilohertz radio frequency AC or pulses with kilo-volt amplitude as shown in Figure 1. It has been known that the discharge generates a weakly ionized gas and charged particles influenced by the electric field can deliver momentum to the neutral particles ${ }^{1,2,3}$. Although the electric field reverses polarity between the two half cycles, the resultant neutral flow is an unidirectional wall jet type flow due to the asymmetric geometry and charged particle behavior ${ }^{4,5,6}$. On the other hand, the disparity between the positive-going uniform discharge and the negative-going non-uniform is regarded as a key role in the efficiency of momentum coupling by some researchers ${ }^{7}$. This is also explained by the higher filamentary discharge during the positive half cycle of the applied sine wave compared to the negative ${ }^{8}$.

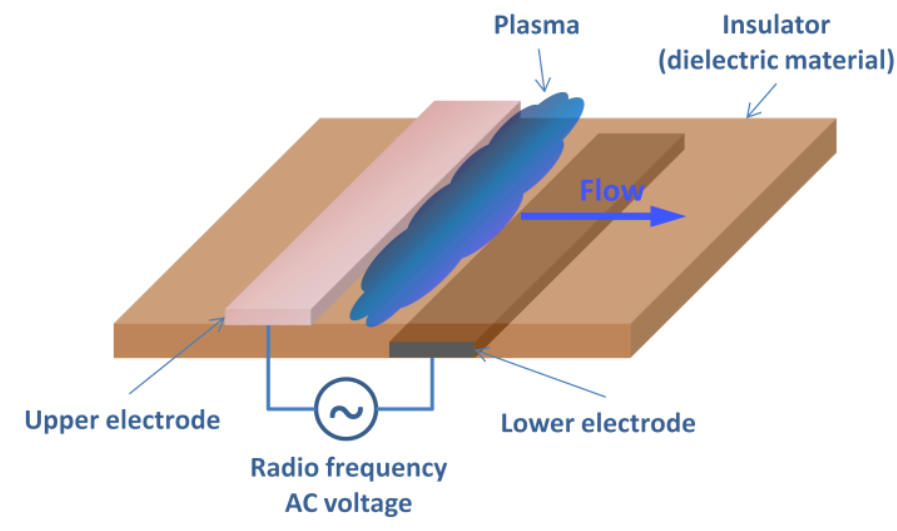

Figure 1 Dielectric-barrier discharge configuration

While the DBD-based actuator exhibits potential as a control device, the performance characteristics such as generated force and power consumption depend on the type of discharge, applied voltage and material of the insulator. There are several operating modes such as streamer or filamentary, glow and coupled ${ }^{9}$ in the dielectric barrier discharge, and a homogeneous low-temperature discharge at atmospheric pressure is of great interest among researchers because of its energy efficient ionization (non-thermal) ${ }^{10}$ and versatile of applications ${ }^{11}$. 
The dielectric-barrier discharge-based plasma actuator has been widely studied for its flow control application. However, in spite of its inherent advantages (no moving parts and vast control potential), little insight is available regarding efficient operating conditions to accommodate various performance needs. With relatively high magnitudes of applied voltage $(15 \mathrm{kV}$ at $5-10 \mathrm{kHz}$ AC) for uniform discharge, the force generated by a single actuator is less than $10 \mathrm{mN} / \mathrm{m}$ in air ${ }^{12}$. The flow velocity induced by a single actuator is usually less than $5 \mathrm{~m} / \mathrm{s}$ for pulsed input voltage ${ }^{13}$ as well as sinusoidal voltage waveform ${ }^{14}$. In their efforts to understand the operating mechanism of the actuator, various researchers have conducted parametric studies to identify trends and if possible optimal conditions. The effects of electrode gap and width ${ }^{14}$, wave form of applied voltage and gas species ${ }^{15}$, frequency and amplitude of applied voltage, dielectric material ${ }^{14,15,16}$, pressure of neutral gas ${ }^{17}$ on the induced flow velocity and/or power efficiency have been reported.

From the previous parametric studies, some features of the correlation between variables have been deduced. Higher voltage, frequency, and rate of voltage increase result in higher force generation or induced velocity ${ }^{14-16,18}$. Materials with larger dielectric constant $\left(\varepsilon_{\mathrm{d}}=30\right.$ compared to 2$)$ are observed to produce larger force due to the increase in electric field and plasma volume although at the cost of increased power ${ }^{16}$. In the same way, thinner dielectric material induces higher flow velocity until the electric field is high enough to produce filamentary discharge which induces smaller momentum transfer to the neutral flow ${ }^{14}$. Although some parametric trends can be explained through the actuator mechanism, the overall performance is affected by many parameters that are correlated to each other. Hence it is hard to identify optimal design of the actuator with reasonable fidelity purely based on independent trends.

Although the related phenomena have been well captured, since the experimental analysis is bounded by the difficulty of measurement, the numerical approach is crucial to understanding the mechanism and physics of the DBD plasma actuator. Recently, the numerical approaches have been improved to simulate the complex phenomena with qualitative comparison to the experiments. Boeuf et al. ${ }^{19}$ use the fluid modeling approach to study the effect of the negative ions, which is important for air chemistry. Font et al. ${ }^{20}$ made a comparison between the particle (PICDSMC) and fluid plasma simulations, and analyzed the asymmetry in the forward and backward cycles and spatial non-neutrality in oxygen. Likhanskii et al. ${ }^{21}$ demonstrate the use of positive pulses with a positive bias and report an improved performance in force generation. Roy et al. ${ }^{22}$ use eight charged and neutral species for $\mathrm{N}_{2} / \mathrm{O}_{2}$ air chemistry simulation, observing the existence of decelerating force downstream of the powered electrode which deteriorates the performance of actuators.

In spite of these recent efforts to accurately capture the actuator physics, significant strides need to be made to integrate these models with the flow physics to study complex flow control applications. Specifically there is significant difference in plasma and neutral flow time scales at low Reynolds numbers ${ }^{23}$ which makes such computations inefficient and infeasible for most practical problems. Anticipating their need, reduced order models have been developed concurrently to accommodate various applications. Instead of using time-variant high fidelity discharge models, a phenomenological model representation is proposed ${ }^{5}$ to approximate averaged body force field. It enables the simulation of complex flow fields at a much smaller computational cost. It has been applied to the flow control in low Reynolds number airfoil ${ }^{24,25}$, and low-pressure turbine ${ }^{26}$, and separation elimination/delay has been observed. The present effort using surrogate models assists in improving the earlier linear field/phenomenological approach.

The surrogate-based optimization (SBO) approach has been successfully used in the design problems using computationally expensive simulations ${ }^{27,28}$. With limited numerical simulations, the surrogates enable us to generate reliable approximation to the solution over a design space and assess the sensitivity and correlation of the various parameters. They are basically analytical representations relating independent (design) variables to dependent variables (objective functions) with a reasonable behavior. There are widely used models - polynomial response surface approximation (PRS), Kriging (KRG), radial basis neural network (RBNN) and weighted average of multiple surrogate models (MS or parametric weighted surrogate model $)^{29}$. Since the error due to the approximation is affected by various factors such as number of design points, the design of experiments, and behavior of the physical system, the surrogate model needs to be carefully chosen. The optimization process in many cases consists of multiple objectives containing competing factors that can be simplified by ignoring insignificant parameters using global sensitivity analysis (GSA). The iterative design refinement and Pareto front analysis that contains all the possible optima can help identify the global optimum solution.

The present study focuses on understanding the effect of three chosen parameters - waveform and frequency of the applied voltage and dielectric constant of the insulator on the DBD actuator performance - power input and generated flow directional force - using surrogate models. The main objective is to gain an idea of the impact of those variables which have significant interplay. To simplify the problem the computational model with relatively 
simple chemistry of helium as against air is employed. Other variables that are known to have significant impact are fixed to make the problem manageable including geometry of the actuator. Using the surrogate-based technique parametric relations between the design variables and objective functions have been identified. Error and performance of the various surrogate models for this application is also be discussed in detail.

\section{Governing Equations and Numerical Approach}

The set of governing equations used in modeling the DBD actuator are the continuity and momentum equations derived from the Boltzmann equation and the electric field equation from the Maxwell's equations. Since the atmospheric pressure is high enough to assume the local thermodynamic equilibrium, the fluid model is reasonably accurate and the local electric field density (E/N) can be used to approximate the phenomena related to the collision processes - ionization/recombination, diffusion and drift - instead of solving the energy equation ${ }^{30}$. Governing equations are given as Eq. (1) (3) for only two species $-\mathrm{He}^{+}$(subscript $\mathrm{p}=\mathrm{i}$ ) and electron (subscript $\mathrm{p}=\mathrm{e}$ ) - for simplicity in this paper.

$$
\begin{aligned}
& \frac{\partial \mathrm{n}_{\mathrm{p}}}{\partial \mathrm{t}}+\nabla \cdot\left(\mathrm{n}_{\mathrm{p}} \mathbf{u}_{\mathrm{p}}\right)=\mathrm{n}_{\mathrm{e}} \mathrm{S}_{\mathrm{ie}}-\mathrm{rn}_{\mathrm{i}} \mathrm{n}_{\mathrm{e}} \\
& \mathrm{n}_{\mathrm{p}} \mu_{\mathrm{p}} \mathbf{E}-\nabla\left(\mathrm{n}_{\mathrm{p}} \mathrm{D}_{\mathrm{p}}\right)=\mathrm{n}_{\mathrm{p}} \mathbf{u}_{\mathrm{p}} \\
& \nabla \cdot\left(\varepsilon_{\mathrm{d}} \mathbf{E}\right)=\frac{\mathrm{q}_{\mathrm{i}} \mathrm{n}_{\mathrm{i}}-\mathrm{q}_{\mathrm{e}} \mathrm{n}_{\mathrm{e}}}{\varepsilon_{0}}
\end{aligned}
$$

The equation (2) is the well-known drift-diffusion equation, which is valid also for ions in the high pressure (atmospheric regime) discharge. To solve this set of equations the source terms are handled with $4^{\text {th }}$ order backward differentiation formula (BDF) and the Poisson equation with the algebraic multigrid method ${ }^{23}$. And the second-order central difference and upwind methods are employed for the diffusion and convection terms respectively. The number densities and electric field are coupled by solving the Poisson equation between the predictor and corrector steps where the first order source splitting is used as noted in Ref. 30. The coefficients of gaseous properties of helium regarding particle collisions and ionization/production are obtained from Ref. 1, 2, and 31.

The computational domain with the actuator geometry is presented in Figure 2. The thickness of the insulator $\left(h_{d}\right)$ is set as $0.5 \mathrm{~cm}$ and the lengths of upper $\left(l_{e u}\right)$ and lower electrodes $\left(l_{e l}\right)$ are $0.2 \mathrm{~cm}$ same as the gap distance $\left(d_{e}\right)$. The applied voltage to the upper electrode has sinusoidal shape but the positive-to-negative half cycle ratio, $\mathrm{r}_{\mathrm{f}}$ can be varied. Boundary conditions for the charge species at the dielectric surface are set to satisfy the current continuity that allows the accumulation of particles, and only electrons are allowed to be absorbed in the upper electrode without the secondary emission. Gas pressure of helium is set as $300 \mathrm{mmHg}$, and the ion temperature is $300 \mathrm{~K}$. The electron temperature is calculated as a function of the local electric field strength using a local field approximation approach, which is discussed in detail in Ref. 23.
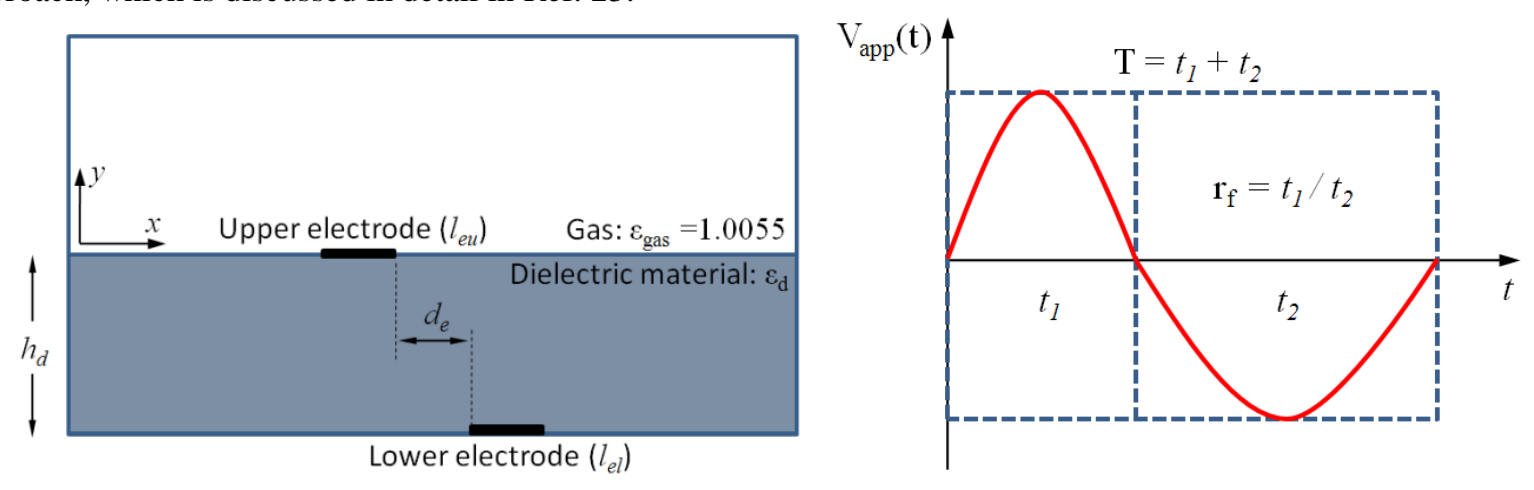

Figure 2 Computational domain and applied waveform

\section{Surrogate Models and Optimization Methodology}

Among the many possible parameters affecting the actuator performance, three are chosen as design variables to assess their impact on the actuator efficiency. The dielectric constant of the insulator material $\left(\varepsilon_{\mathrm{d}}\right)$, frequency of the 
applied voltage $\left(f_{v}\right)$ and positive-to-negative half cycle ratio $\left(\mathrm{r}_{\mathrm{f}}\right)$ are chosen for the preliminary parametric study because they are among the key parameters which have non-simple effects on the resultant force by affecting both of the positive and negative peak value of domain averaged force and asymmetry in its waveform ${ }^{6}$. However, there are numerous parameters, which are known to affect the generated force and power. The peak magnitude of sinusoidal voltage and the size of electrode are also decisive parameters in force generation, such as power dependency of the force on the voltage peak ${ }^{32}$. The constraint of each design variable is devised by considering the existing choice of materials and the general working conditions of previous DBD actuators. The objective functions are chosen to represent the actuator performance, namely the time and domain averaged $\mathrm{x}$-directional force $\left(\mathrm{F}_{\mathrm{x}, \mathrm{ST}}\right)$ and average power input to the circuit $\left(\mathrm{P}_{\mathrm{T}}\right)$. The time and domain averaged Lorentzian force to the charged particles is assumed to be equivalent to the body force acting on the neutral gas, especially at atmospheric pressure conditions. The actual power input to the discharge device can be calculated by considering the charge and displacement currents in the volume of the medium ${ }^{33}$. However in this study only the charge current through the upper electrode is considered for simplicity. The definitions and parameter ranges are presented in Table 1.

Table 1 Design variable constraints and objective functions

\begin{tabular}{|c|c|c|}
\hline & Design variables & Constraints \\
\hline$\varepsilon_{\mathrm{d}}$ & $\begin{array}{l}\text { Dielectric constant of the } \\
\text { insulator }\end{array}$ & $2 \leq \varepsilon_{\mathrm{d}} \leq 15$ \\
\hline $\mathrm{f}_{\mathrm{v}}$ & $\begin{array}{l}\text { Frequency of the applied } \\
\text { voltage }(\mathrm{kHz})\end{array}$ & $5 \leq \mathrm{f}_{\mathrm{v}} \leq 20$ \\
\hline$r_{f}$ & $\begin{array}{l}\text { Positive-to-negative half } \\
\text { cycle ratio }\end{array}$ & $0.5 \leq \mathrm{r}_{\mathrm{f}} \leq 1.5$ \\
\hline & Objective functions & Definitions \\
\hline$-\left|\mathrm{F}_{\mathrm{X}, \mathrm{ST}}\right|$ & $\begin{array}{l}\text { Time and domain averaged } \\
\mathrm{x} \text {-directional force }(\mathrm{mN} / \mathrm{m})\end{array}$ & $\mathrm{F}_{\mathrm{x}, \mathrm{ST}} \equiv \frac{1}{\mathrm{ST}} \int_{\mathrm{S}} \int_{\mathrm{T}} \mathrm{F}_{\mathrm{x}}(\overline{\mathrm{r}}, \mathrm{t}) \mathrm{dtd} \overline{\mathrm{r}}$ \\
\hline $\mathrm{P}_{\mathrm{T}}$ & $\begin{array}{l}\text { Power input for one cycle by } \\
\text { the charge current through } \\
\text { the upper electrode }(\mathrm{W})\end{array}$ & $\begin{array}{c}\mathrm{P}_{\mathrm{T}} \equiv \frac{1}{\mathrm{~T}} \int_{\mathrm{T}} \mathrm{I}(\mathrm{t}) \mathrm{V}(\mathrm{t}) \mathrm{dt} \\
\text { where } \mathrm{I}(\mathrm{t})=\int_{\mathrm{l}_{\mathrm{eu}}}\left(\mathrm{q}_{\mathrm{i}} \mathrm{n}_{\mathrm{i}}(\mathrm{t}) \mathrm{u}_{\mathrm{y}, \mathrm{i}}(\mathrm{t})-\mathrm{q}_{\mathrm{e}} \mathrm{n}_{\mathrm{e}}(\mathrm{t}) \mathrm{u}_{\mathrm{y}, \mathrm{e}}(\mathrm{t})\right) \mathrm{dx}\end{array}$ \\
\hline
\end{tabular}

The objectives of the optimization problem are maximizing $\mathrm{F}_{\mathrm{x}, \mathrm{ST}}$ and minimizing $\mathrm{P}_{\mathrm{T}}$. However, as will be discussed later, since there are cases which produce the negative $F_{x, S T}$, one objective is chosen as minimizing $-\left|F_{x, S T}\right|$ for the convenience of minimizing both objective functions.

Since the number of the sampling points is restricted by the computational cost, the design of experiments needs to be chosen carefully. Some of the most popular approaches such as the combination of face-centered composite design (FCCD), Latin-hypercube sampling (LHS), distance-based (DB) designs and their modifications are used. By spreading the design points towards constraints FCCD is efficient for second-order design in a cuboid design space, and LHS provides space-filling data set with the even chance for each design variable. DB simply generates design points to be evenly distributed in space, thus can cover complicated design space properly ${ }^{34}$. Considering its iterative nature and the computational expense, the number of sampling points at each refined level is set to 20 which is usually sufficient for $2^{\text {nd }}$ order polynomial response surface.

Four different surrogate models such as $2^{\text {nd }}$ order polynomial response surface, Kriging, radial basis neural network, and multiple surrogate which is the weighted combination of the rest- are applied to generate the analytic response of the actuator model. ${ }^{28}$ The weight of each model in the multiple surrogates is set using the nonparametric surrogate filter which gives higher value for the surrogate with the smaller square root of predicted residual sum of squares (PRESS) error by evaluating it to be proportional to the sum of the PRESS of other surrogates $^{29}$. Main and total effects of variables in the global sensitivity analysis are computed using the Gaussian quadrature. 
For the multi-objective optimization of minimizing two objective functions, the Pareto optimal set is constructed by seeking the non-dominated points in the objective function space. This type of searching the best trade-off solutions is accompanied by the multiple design space refinements based on the surrogate model statistics in the previous level.

\section{A. Surrogate modeling}

\section{Results and Discussion}

The first level design of experiments - level 0 - using the combination of FCCD and LHS and the simulation result of those 20 points are presented in Figure 3. Although the sampled points are well distributed in the design space, the response points cluster in some parts of the response space as in Figure $3 \mathrm{~b}$ ). As a result it is hard to get an idea of the objective function dependency on the design variables with sufficient accuracy, but some noteworthy features can be observed from the contours. With higher dielectric constant of the insulator both power and magnitude of force, $\left|\mathrm{F}_{\mathrm{X}, \mathrm{ST}}\right|$ tend to increase. The applied voltage with the lower frequency leads to lower power. The ratio of first and second half cycle shows more complex effects and makes it hard to deduce any tendency.

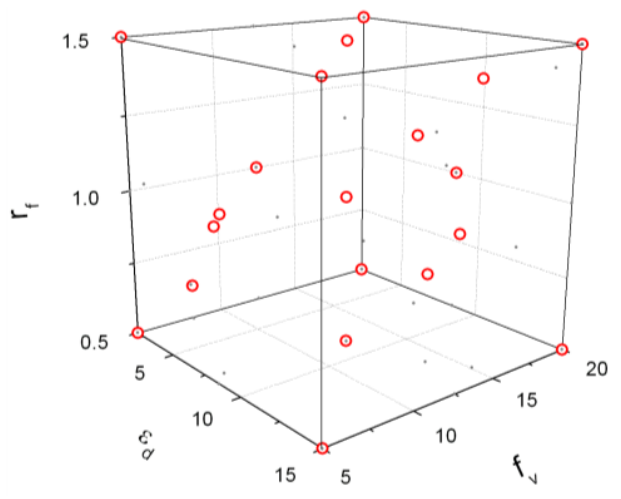

a) Design of experiments: combination of FCCD and LHS
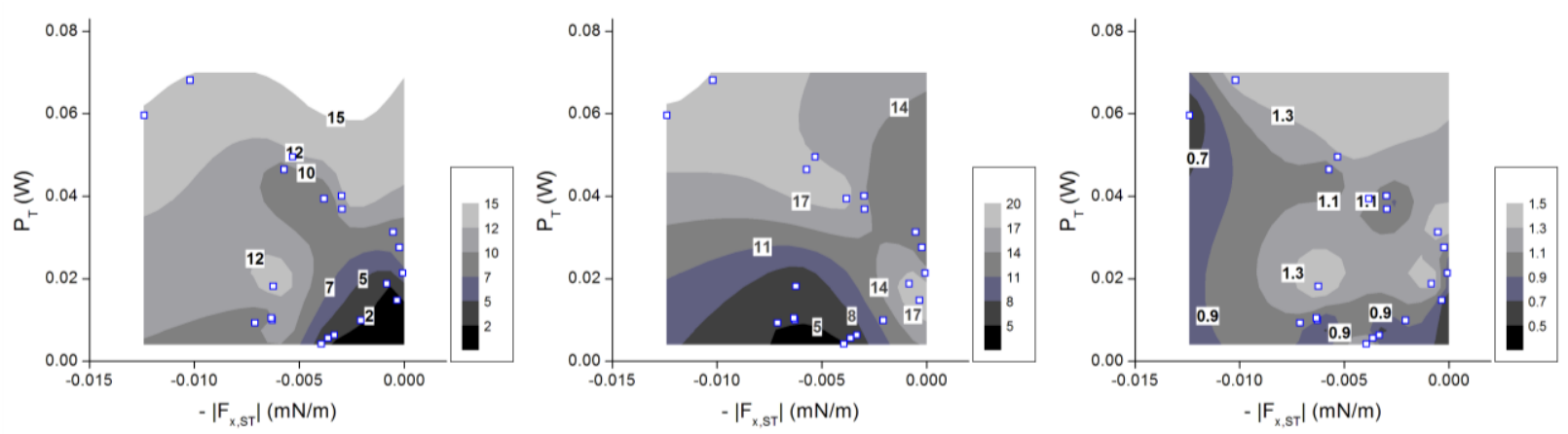

b) Design variable contours with simulation result in objective function space: $\varepsilon_{d}, f_{v}$ and $r_{f}$

Figure 3 Design of experiments and their simulated results - level 0

The surrogate models are obtained using these sampled points and the PRESS errors of them are presented in Table 2. Due to the insufficient number of sampled points and their complex response, significant PRESS errors exist at this level especially in force prediction. In this case, however, the Kriging model has the best performance in predicting the force, while the multiple surrogate model does the same for power.

As a compromise between the errors in force and power, the multiple surrogate model is chosen and 29,791 grid points covering the whole design space are employed to predict the response based on it, as presented in Figure 4. Firstly, there are two Pareto fronts in two distinctive regions that indicate higher magnitude of force. Though they both lie in the same side of force axis due to adopting the absolute values of the force, the one with higher power corresponds to the negative (minus x-direction in Figure 2) force generation, and the lower to the positive. In 
magnitude the negative force generation is larger than the positive, which can be more desirable from a force generation perspective while the positive force does the same for power efficiency. The power ratio for those two regions is about 5 6 compared to the force ratio of 2. Secondly, the shape and density of data points around the Pareto fronts in two regions are much different. Since the calculated points are generated so as to cover the design space evenly, the coarser distribution of result points and those forming the Pareto front in the higher power region indicate higher sensitivity of the result, especially for the averaged force generation to the design variables, compared to the lower power region.

Table 2 PRESS errors of the surrogate models - level 0

\begin{tabular}{ccccc}
\hline PRESS & Kriging & $\begin{array}{c}\text { Polynomial } \\
\text { response }\end{array}$ & $\begin{array}{c}\text { Radial basis } \\
\text { neural network }\end{array}$ & $\begin{array}{c}\text { Multiple } \\
\text { surrogate }\end{array}$ \\
\hline$-\left|\mathrm{F}_{\mathrm{x}, \mathrm{ST}}\right|$ & $0.0020(16)^{*}$ & $0.0027(22)$ & $0.0095(77)$ & $0.0028(23)$ \\
\hline $\mathrm{P}_{\mathrm{T}}$ & $0.0032(5.0)$ & $0.0033(5.2)$ & $0.0063(9.9)$ & $0.0023(3.6)$ \\
\hline & $*:(\mathrm{)}) \%=100 \times$ PRESS $/\left(\mathrm{X}_{\max }-\mathrm{X}_{\min }\right), \mathrm{X}=-\left|\mathrm{F}_{\mathrm{x}, \mathrm{ST}}\right|$ or $\mathrm{P}_{\mathrm{T}}$ in level 0
\end{tabular}

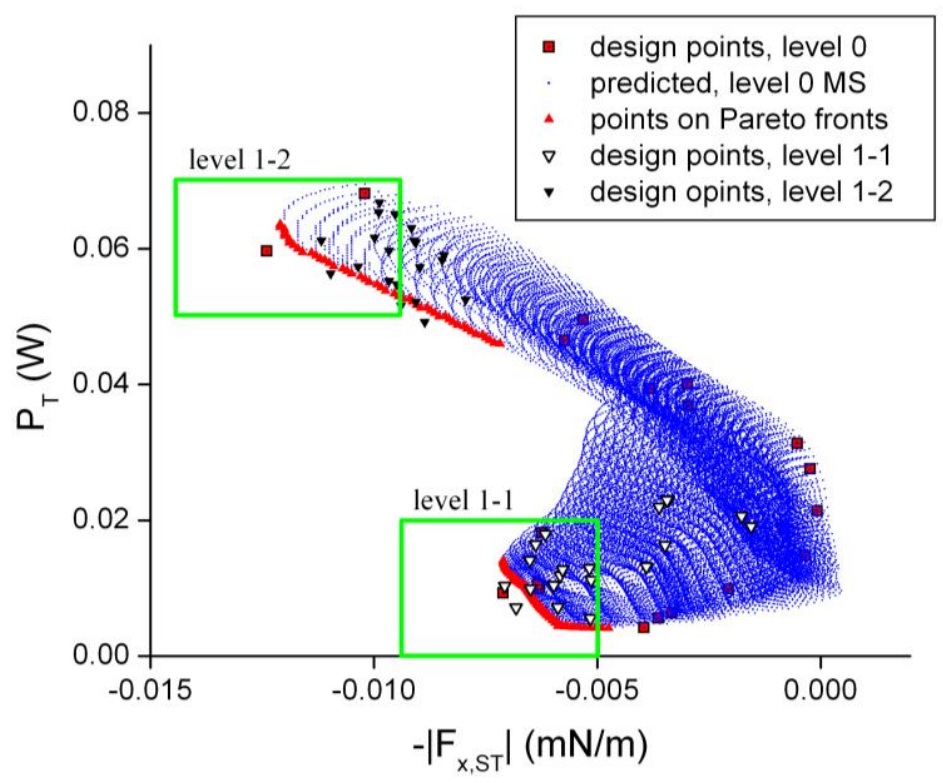

Figure 4 Design and predicted points and Pareto fronts by the multiple surrogate model in level 0

The mechanism of the force generation over the two half-cycles has been a subject of interest with different suggestions such as, whether it consists of two consecutive positive or a positive-negative alternating patterns ${ }^{5}$. It has been reported by some researchers that the dominant positive and small negative force generations for the first and second half cycles respectively exist for sinusoidal voltage excitation ${ }^{6,35}$ or pulse-mode operation ${ }^{36}$. Because of the different charged species chemistry and other parameters such as geometry it is difficult to compare the solution directly. Also in the numerical models there are other factors such as boundary treatment, temporal and spatial resolution and domain size, surface reaction modeling which affect the force. In the current study there are positive and negative alternating contributions of force generation in two half cycles, and in a certain part of design space the negative portion excels the positive, resulting in a negative force generation.

Since the distribution of design points around those interesting regions is too sparse, two windowed constrains are used to specify refinement regions, as candidates where Pareto front can reside.

$$
\text { Level 1-1, low power region: } \begin{array}{rrr}
-0.009 & \leq-\left|\mathrm{F}_{\mathrm{x}, \mathrm{ST}}\right| \leq-0.005 & (\mathrm{mN} / \mathrm{m}) \\
0 & \leq \mathrm{P}_{\mathrm{T}} \leq 0.02 & \text { (W) }
\end{array}
$$


Level 1-2, high power region: $-0.014 \leq-\left|\mathrm{F}_{\mathrm{x}, \mathrm{ST}}\right| \leq-0.009 \quad(\mathrm{mN} / \mathrm{m})$

$$
0.05 \leq \mathrm{P}_{\mathrm{T}} \leq 0.07 \quad(\mathrm{~W})
$$

The design variable constraints corresponding to these objective function constraints are generated based on Kriging $^{28}$ model considering the PRESS values in Table 2 and a conservative choice of the space defined by the constraints, i.e. to cover the more space as possible. Figure 5 shows constraint surfaces in the design space that is generated approximately by connecting neighboring grid points satisfying constraint criteria. There exist multiple regions divided by the surfaces and the common space enclosed by force and power constraints corresponds to the refinement region. Since these surfaces are contours of constant force or power, it can be said that objective functions are relatively insensitive to the dielectric constant.

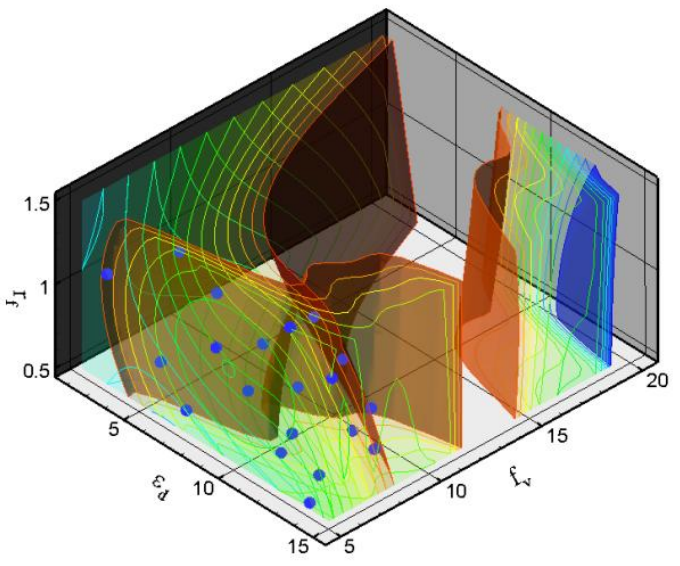

a) level 1-1: low power region $\left(\mathrm{P}_{\mathrm{T}}\right.$ : diagonal surface)

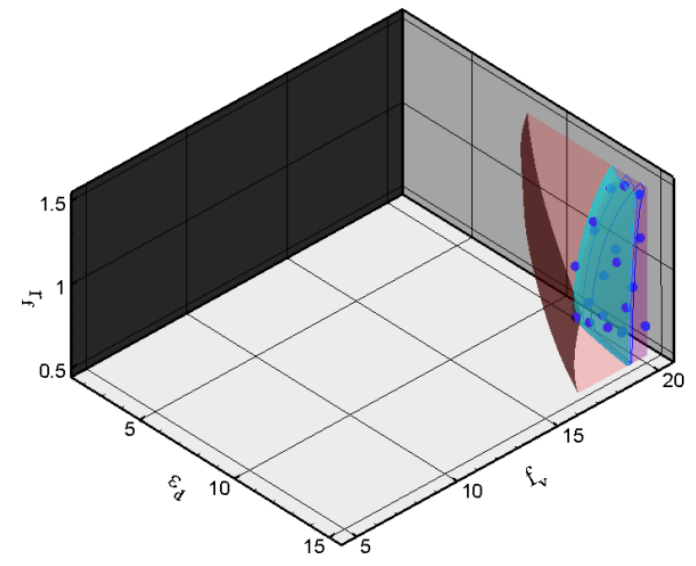

b) level 1-2: high power region $\left(\mathrm{P}_{\mathrm{T}}\right.$ : larger surface)

\section{Figure 5 Constraints, contours and design points for refinement in design space}

Since the design space corresponding to level 1-1 and 1-2 constraint windows is an irregular shape, it is impossible to use the design of experiments for a rectangular hexahedron or sphere. To generate design points LHS is used to cover the space with as small number of points as possible, and at the same time, distance-based design which ensures even distribution within the space is adopted. 20 points in each constraint design space are generated by this approach as shown in Figure 5 with the constraint surfaces.

Table 3 PRESS errors of the surrogate models - level 1-1

\begin{tabular}{ccccc}
\hline PRESS & Kriging & $\begin{array}{c}\text { Polynomial } \\
\text { response }\end{array}$ & $\begin{array}{c}\text { Radial basis } \\
\text { neural network }\end{array}$ & $\begin{array}{c}\text { Multiple } \\
\text { surrogate }\end{array}$ \\
\hline$-\left|\mathrm{F}_{\mathrm{x}, \mathrm{ST}}\right|$ & $5.2 \times 10^{-4}(9.5)^{*}$ & $\begin{array}{c}3.7 \times 10^{-4}(6.7) \\
2.7 \times 10^{-4}(4.9)\end{array}$ & $3.3 \times 10^{-4}(6.0)$ \\
\hline $\mathrm{P}_{\mathrm{T}}$ & $1.9 \times 10^{-4}(1.1)$ & $\begin{array}{c}1.4 \times 10^{-4} \\
(0.80)\end{array}$ & $6.9 \times 10^{-4}(3.9)$ & $1.2 \times 10^{-4}(0.69)$ \\
\hline & $*:(\mathrm{)}) \%=100 \times \mathrm{PRESS} /\left(\mathrm{X}_{\max }-\mathrm{X}_{\min }\right), \mathrm{X}=-\left|\mathrm{F}_{\mathrm{x}, \mathrm{ST}}\right|$ or $\mathrm{P}_{\mathrm{T}}$ in level 1-1
\end{tabular}

Table 4 PRESS errors of the surrogate models - level 1-2

\begin{tabular}{ccccc}
\hline PRESS & Kriging & $\begin{array}{c}\text { Polynomial } \\
\text { response }\end{array}$ & $\begin{array}{c}\text { Radial basis } \\
\text { neural network }\end{array}$ & $\begin{array}{c}\text { Multiple } \\
\text { surrogate }\end{array}$ \\
\hline$-\left|\mathrm{F}_{\mathrm{x}, \mathrm{ST}}\right|$ & $1.2 \times 10^{-4}(3.8)^{*}$ & $1.1 \times 10^{-4}(3.4)$ & $3.4 \times 10^{-4}(10.6)$ & $1.1 \times 10^{-4}(3.4)$ \\
\hline $\mathrm{P}_{\mathrm{T}}$ & $2.0 \times 10^{-4}(1.1)$ & $0.55 \times 10^{-4}(0.31)$ & $9.4 \times 10^{-4}(5.3)$ & $0.90 \times 10^{-4}(0.51)$ \\
\hline \multicolumn{5}{c}{$(\mathrm{)})=100 \times \mathrm{PRESS} /\left(\mathrm{X}_{\max }-\mathrm{X}_{\min }\right), \mathrm{X}=-\left|\mathrm{F}_{\mathrm{X}, \mathrm{ST}}\right|$ or $\mathrm{P}_{\mathrm{T}}$ in level 1-2 }
\end{tabular}


The simulated result of design points in each region is used to generate surrogate models. With the refinement, model prediction accuracy is improved both in relative and absolute values as shown in Table 3 and Table 4. It can be seen that the PRESS error for the polynomial response surface in the refined levels is much improved, which means the real complexity is not severe in these refined regions.

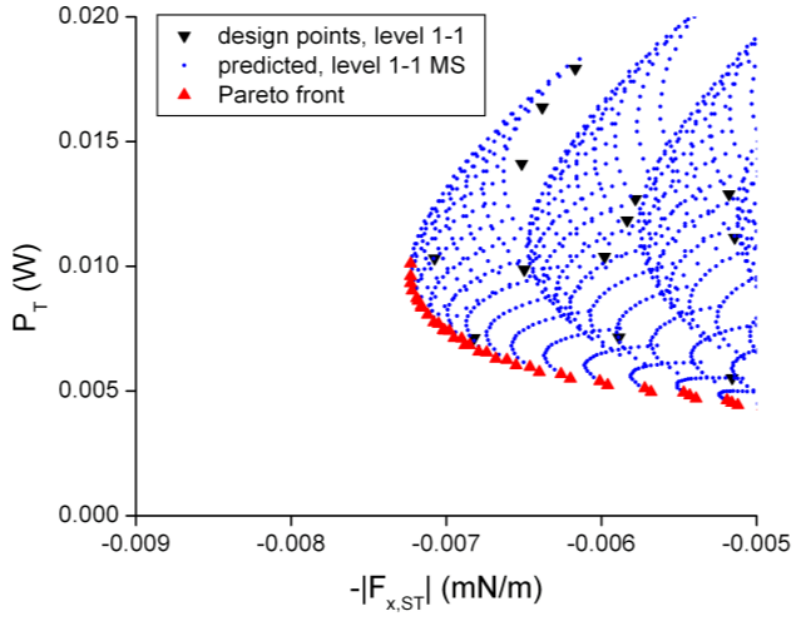

a) level 1-1: multiple surrogate model

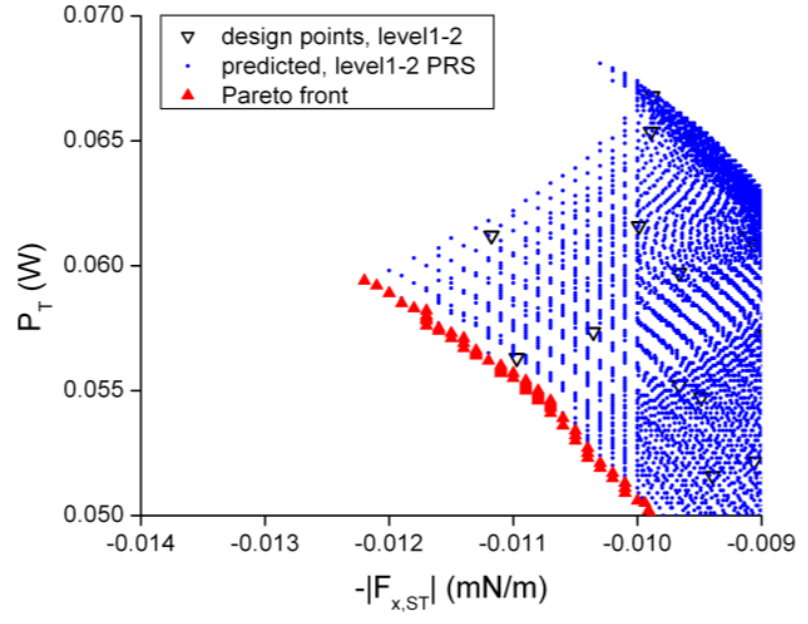

b) level 1-2: polynomial response surface

Figure 6 Design and predicted points and Pareto front in each refinement level

Using the MS in level 1-1 and PRS level 1-2 which have best PRESS values, the Pareto front is constructed again for each data set as shown in Figure 6 a) and b), along with the predicted points by the surrogate models. It can be checked that the majority of design points -13 in the low power region and 15 in the high power region - reside in the constraint regions, which relates the prediction accuracy of surrogate models based on level 0 , although the predicted position of each design point may differ at least as in PRESS values. Although there are differences between the Pareto fronts using level 0 and those using level 1-1 and 1-2, there is consistency in shape and direction of the fronts.

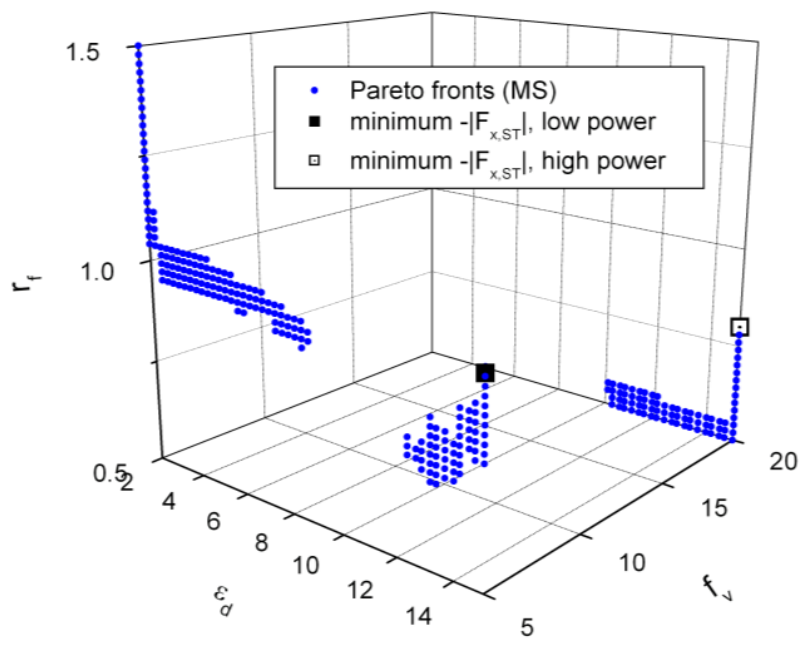

a) level 0

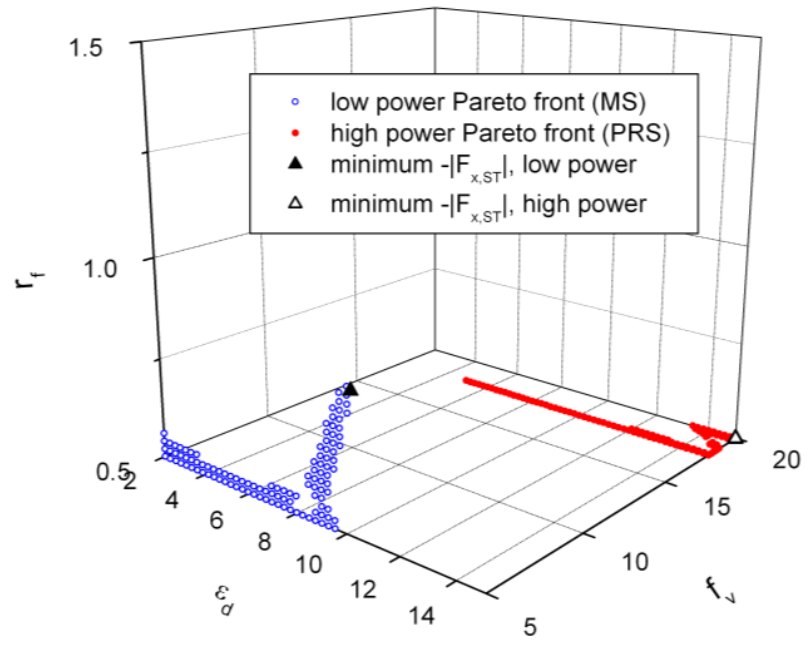

b) level 1-1 and 1-2

Figure 7 Reproduced points corresponding to the Pareto fronts and two design points with minimum -|F $F_{x, S T} \mid$ in low and high power regions 


\section{B. Two distinctive regions and Pareto fronts}

To investigate the design variable variation around the Pareto fronts, surrogate models are used as functions to refer the design space regions which correspond to the fronts. The region calculated based on level 0 is presented in Figure 7 a) and based on level 1 in b). Compared to the prediction by the level 0 surrogate model, the level 1 shows more coherent regions that correspond to two Pareto fronts respectively. The two fronts with high and low power consumptions are separated by the whole design space in terms of the applied voltage frequency.

The most efficient points corresponding to force generation, i.e. minimum in $-\left|\mathrm{F}_{\mathrm{x}, \mathrm{ST}}\right|$ also differ much though they occur at the same frequency of applied voltage, $\mathrm{f}_{\mathrm{v}}$. It can be observed that to follow the Pareto front line of the high power region the dielectric constant, $\varepsilon_{\mathrm{d}}$ can be the major variable, while for the one of the low power region, $\varepsilon_{\mathrm{d}}$ and $r_{f}$ need to be varied. Though it may be inconvenient to vary the material constant such as $\varepsilon_{\mathrm{d}}$ to accommodate a desired objective function state, if proper design variables are chosen, this type of information can be used to establish a basis for the performance of these actuators as flow control devices.

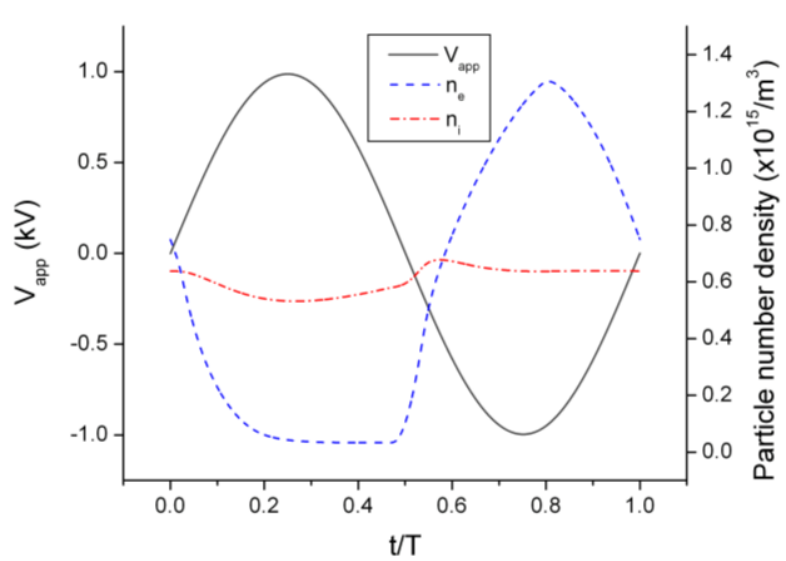

a) low power region: $\varepsilon_{\mathrm{d}}=8.5, \mathrm{f}_{\mathrm{v}}=5.0, \mathrm{r}_{\mathrm{f}}=1.0$

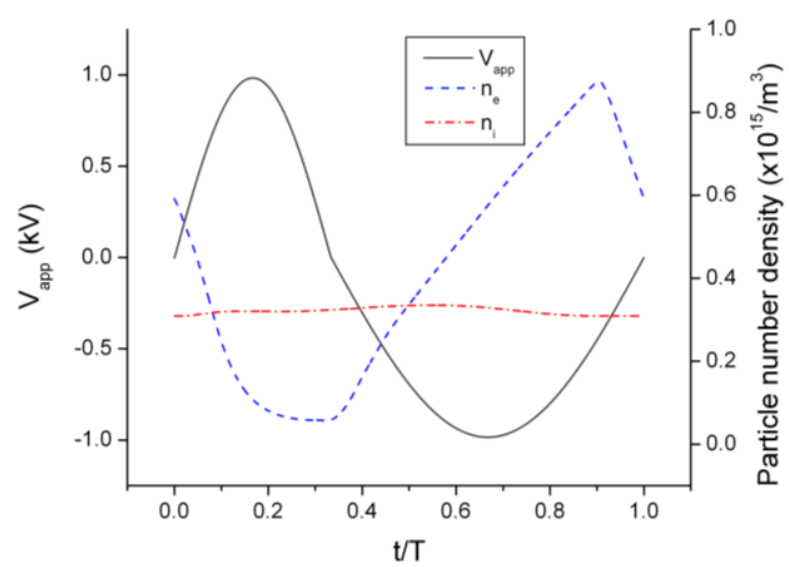

b) high power region: $\varepsilon_{\mathrm{d}}=15.0, \mathrm{f}_{\mathrm{v}}=20.0, \mathrm{r}_{\mathrm{f}}=0.5$

Figure 8 Particle number density history for two design points near two Pareto fronts

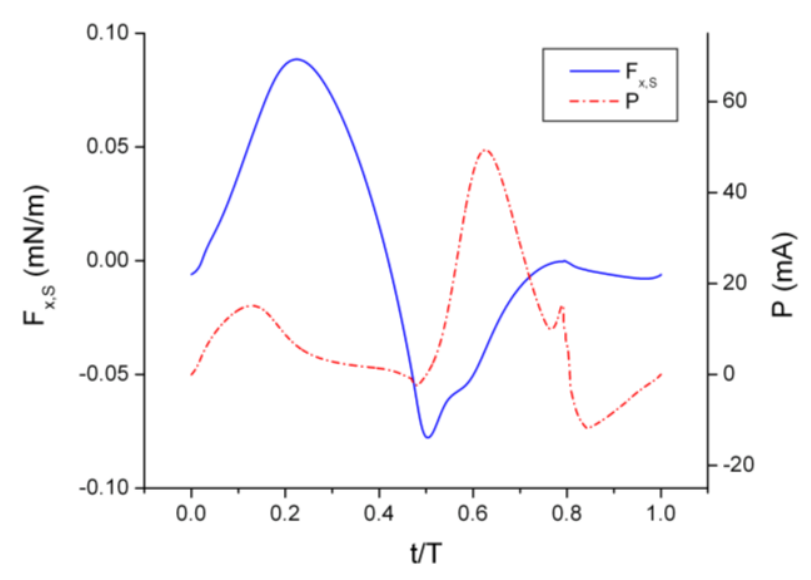

a) low power region: $\varepsilon_{\mathrm{d}}=8.5, \mathrm{f}_{\mathrm{v}}=5.0, \mathrm{r}_{\mathrm{f}}=1.0$

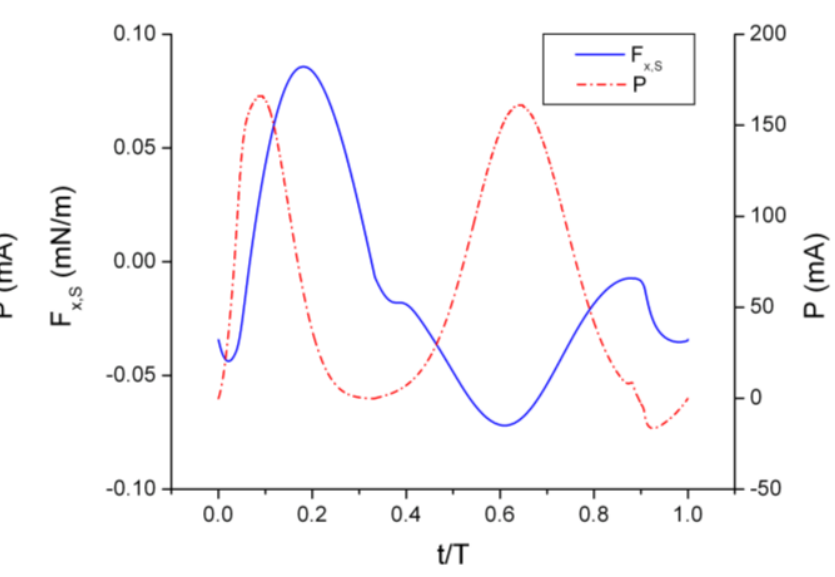

b) high power region: $\varepsilon_{\mathrm{d}}=15.0, \mathrm{f}_{\mathrm{v}}=20.0, \mathrm{r}_{\mathrm{f}}=0.5$

Figure 9 Domain averaged force and power history for two design points near two Pareto fronts

In terms of optimal conditions, it should be mentioned that the optimal points reside in the boundary of design variable constraints - one is for $f_{v}$ and the other is for $f_{v}$ and $r_{f}$. To obtain conditions for optimal performance of the actuator, design space can be extended to cover more space. However, care needs to be taken to consider the discharge operating mode that is known to significantly change the ionization degree as well as power consumption.

To investigate the phenomena in these regions in depth and compare them, two points corresponding to the minimum $-\left|\mathrm{F}_{\mathrm{x}, \mathrm{avg}}\right|$ condition are selected and the time history of solution is compared in Figure $8 \sim$ Figure 9. In 
Figure 8 a) and b) it can be observed that with lower frequency which lies in low power region, domain-averaged ion number density is higher. This can be explained by considering the fact that lower frequency allows more time to generate the particles, which is consistent with the previous research ${ }^{32}$. The electron saturation instances in these cases - about $\mathrm{t} / \mathrm{T}=0.8$ in the low power and 0.9 in the high power - coincide with the start of plateau or second dip in Figure 9, which is also mentioned as one of key factors in the solution difference with different frequency.

From the force history result, one can deduce the effect of the ratio of first and second half cycles, $r_{f}-$ changing the relative influence of discharge in each half cycle. It is thought as an effective parameter changing force history profile and thus adopted as one of design variables for this purpose. Although positive force belongs to the first half cycle and negative to the second, elongating the period of each part in applied electric field does not necessarily induces increased force either in positive or negative. While decreasing $r_{f}$, i.e. increasing the second half cycle corresponds to the decreased $-\left|F_{x, \text { avg }}\right|$ point in the high power region, increasing $r_{f}$ does not mean increasing the magnitude of positive force cycle. The value of $r_{f}$ is about 0.8 for such a point in the low power region according to the multiple surrogate model. The reason is that generating positive force is mainly related to the plateau region of the second half cycle in $\mathrm{F}_{\mathrm{x}}$ time history as in Figure 9.
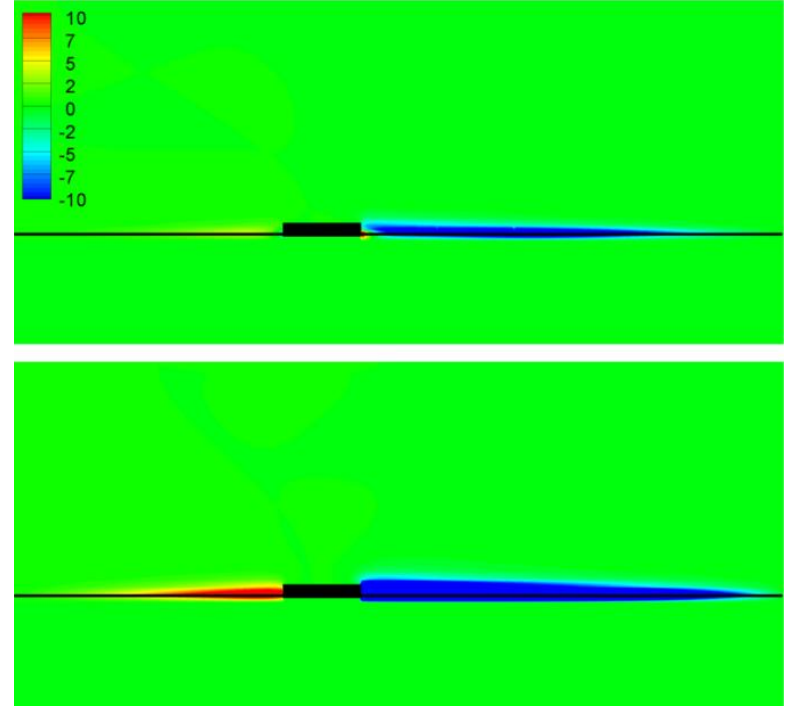

a) $F_{x}\left(N / m^{3}\right)$
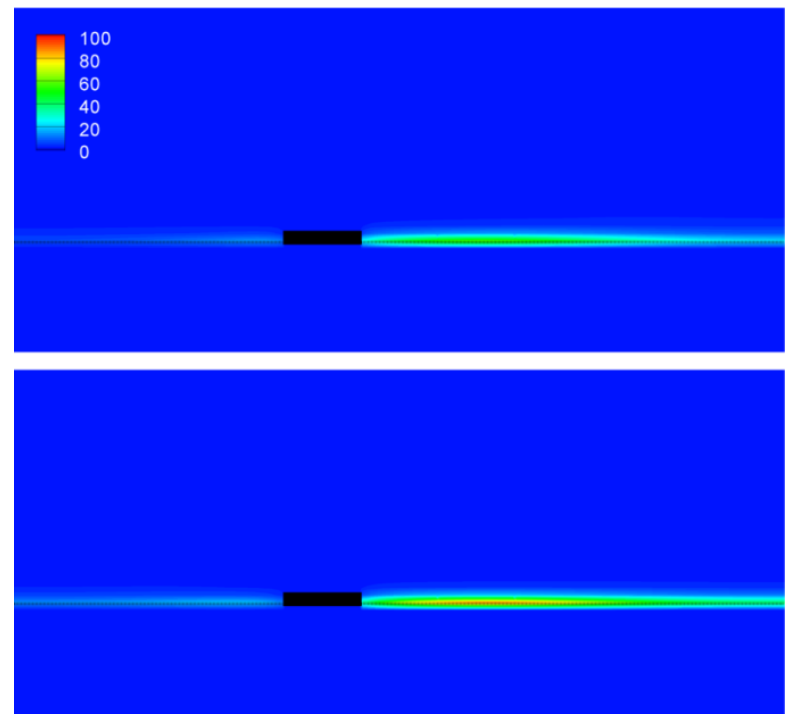

c) $\mathrm{n}_{\mathrm{e}}\left(\times 10^{15} / \mathrm{m}^{3}\right)$
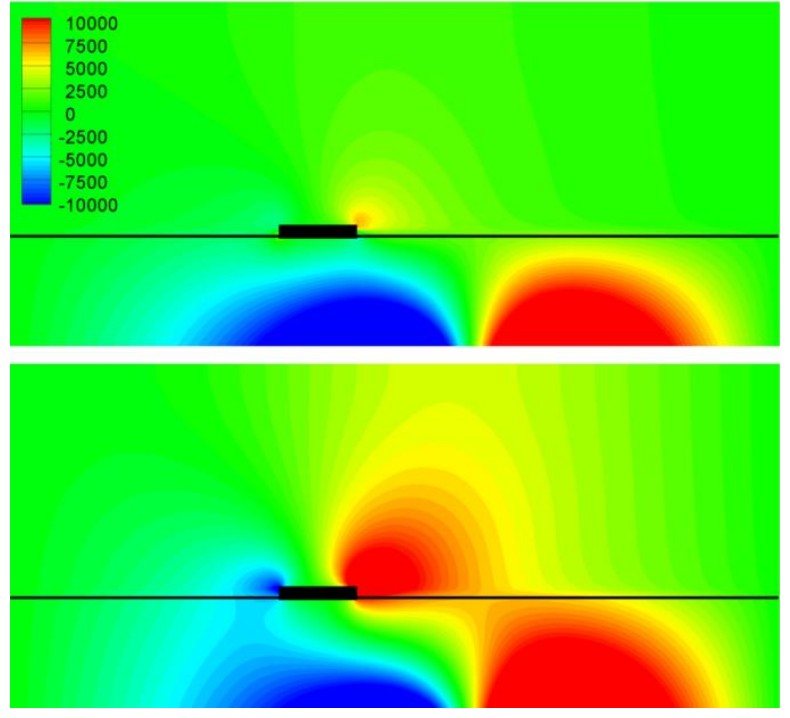

b) $E_{x}(V / m)$
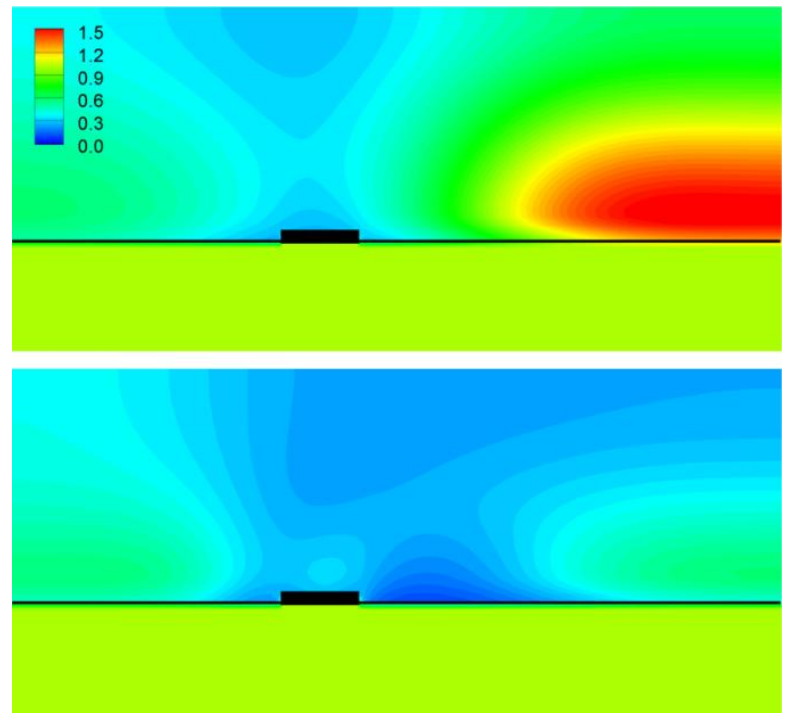

d) $n_{i}\left(\times 10^{15} / \mathrm{m}^{3}\right)$

Figure 10 Solution contour plots at $\mathrm{t} / \mathrm{T}=\mathbf{0 . 9 5}$ (upper: low power region, lower: high power region) 
This phenomenon is mainly affected by the difference in the amount and evolution of the electron and the ion clouds which reside on the dielectric surface. In Figure 10 instantaneous contours of main physical quantities especially around the upper electrode are presented at the moment of $t / T=0.95$ when the phase change in applied voltage is about to occur. As noted in the previous research, force generation mainly occurs near wall and electrode region at this instance, which is caused by electrons accumulated on the dielectric surface and high electric field near the edge of electrode. Ion clouds having been repelled from the surface through the second half cycle compensate the applied electric field as in Figure $10 \mathrm{~d}$ ), resulting in the small magnitude of negative force generation in the later part of the second half cycle, i.e. the plateau region. On the other hand, in the case of higher frequency this ion cloud is much weaker and there is strong electric field near the upper electrode which, with the higher electron density near the wall, results in the second negative peak at the end of the second half cycle.

In terms of $\varepsilon_{\mathrm{d}}$, the same can be observed. In the previous research it has been pointed out that the dielectric constant affects the asymmetry of the first and the second half cycles as well as the amplitude of generated force. These two effects contribute to the average force in the opposite tendencies such that increasing the constant increases the amplitude of force history thus has a tendency of increasing the averaged force generation but also decreases asymmetry of the two half cycles thus decreasing the averaged force generation. As a result, for the low power region the efficient point of force generation in Figure 7 occurs at $\varepsilon_{\mathrm{d}}=10.2$ which is not on the boundary of the design variable range, $2.0 \leq \varepsilon_{\mathrm{d}} \leq 15.0$. However, for the high power region it happens at the maximum value, 15.0 .

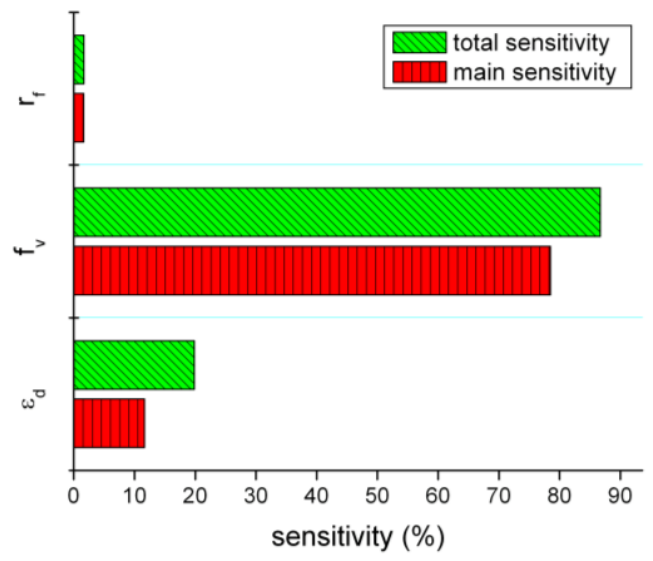

a) $F_{\mathrm{x}, \mathrm{ST}}$, level 1-1

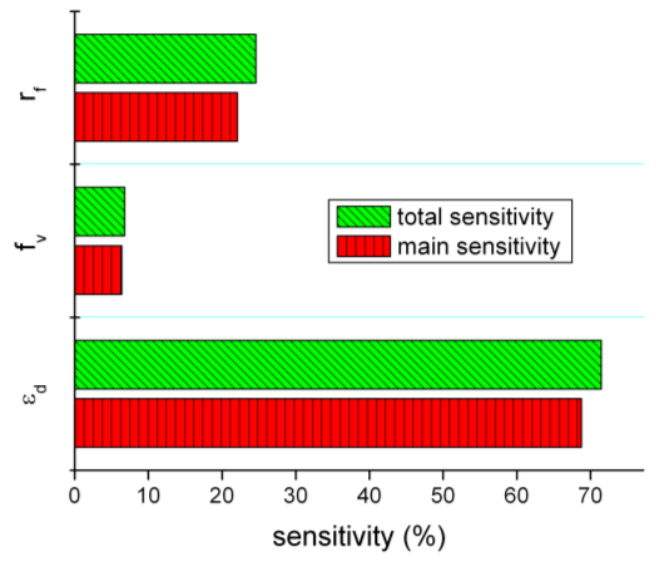

c) $\mathrm{F}_{\mathrm{x}, \mathrm{ST}}$, level 1-2

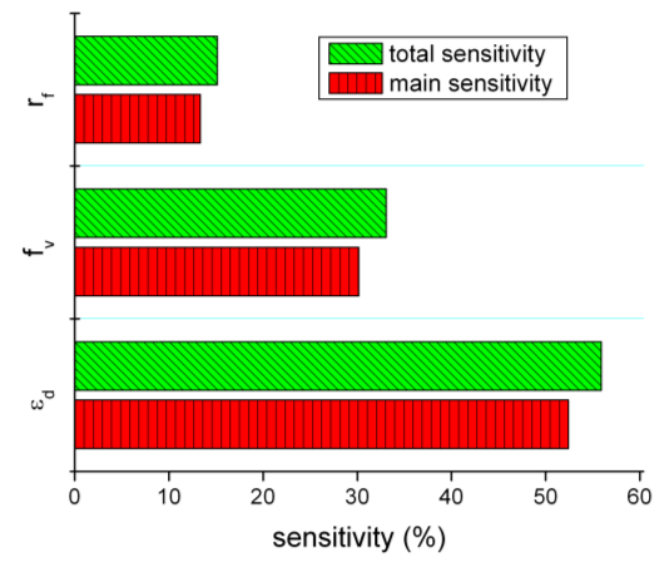

b) $\mathrm{P}_{\mathrm{T}}$, level 1-1

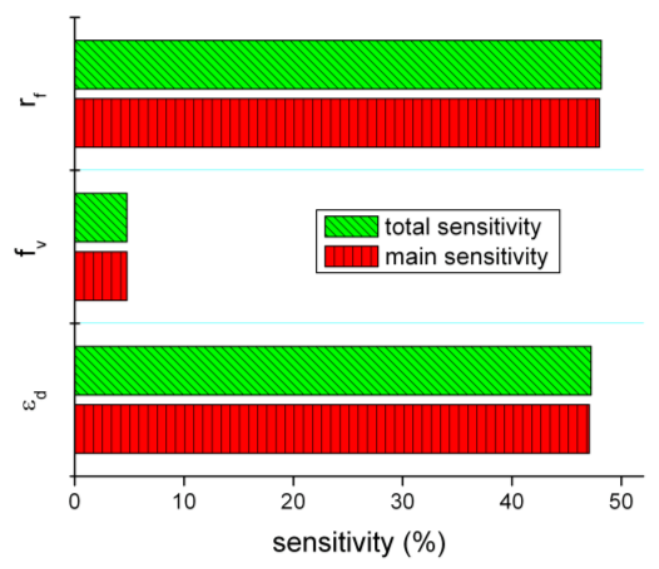

d) $\mathrm{P}_{\mathrm{T}}$, level 1-2

Figure 11 Global sensitivity analysis result

According to the present result, the average force generation has more monotonic dependency on the frequency of applied voltage - at least around the Pareto fronts, for the high power region the higher frequency induces the higher force, and for the lower power region the opposite. But this is because we are dealing with the magnitude of 
the averages force generation ignoring its direction. From the previous research it has been found that the higher force can be obtained with the lower frequency. And with the more prominent effect of the second half cycle the averaged force generation to the negative direction excels the positive in magnitude with higher frequency.

\section{Analysis of global sensitivity and dependency on parameters}

Figure 11 shows the global sensitivity analysis result of polynomial response surface for each refined level. Compared to the level 1-2, level 1-1 has more effect of parameter correlation, which can be identified from the difference between total and main sensitivities. Also, the frequency of applied voltage, $f_{v}$ in level 1-1 has much significant effect on both of average force and power. On the other hand, in the high power refined space (level 1-2) the effect of the positive-to-negative time ratio, $r_{f}$ is prominent, and $f_{v}$ affects much less. On the other hand, the insulator dielectric constant is always important.
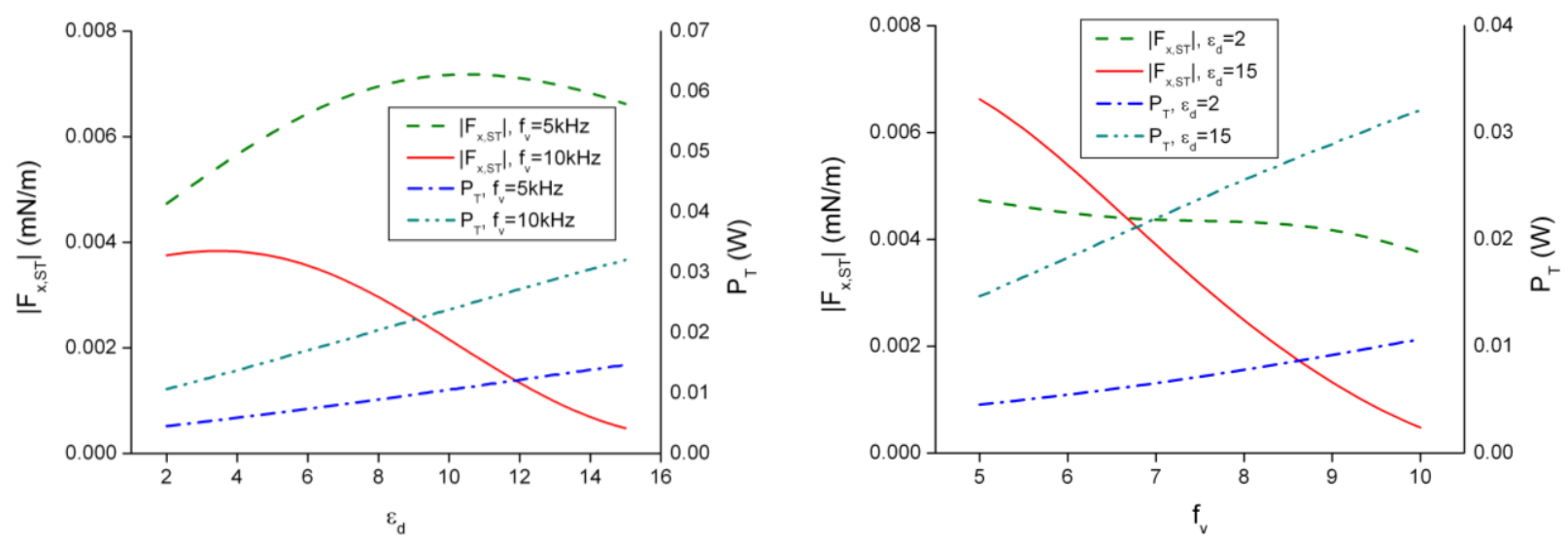

a) $\mathrm{r}_{\mathrm{f}}=1.0$, level $1-1$
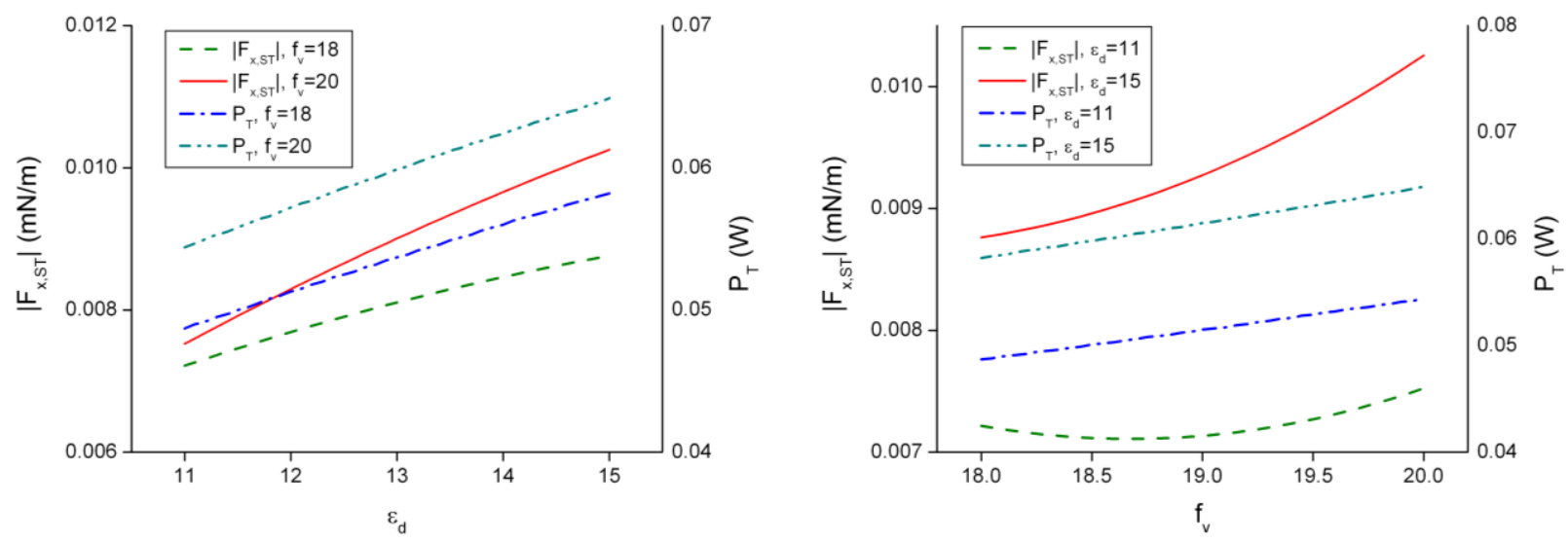

b) $\mathrm{r}_{\mathrm{f}}=1.0$, level $1-2$

\section{Figure 12 Local dependency on parameters}

To see the local dependency of the objective functions on each parameter while keeping others constant, variations are compared for one parameter while fixing boundary values of other parameters which are based on the surrogate with best PRESS error in Table 2 Table 4 and its predicted parameter constraints. While $r_{\mathrm{f}}$ is kept as 1 , the sensitivity on the applied frequency and dielectric constant is shown in Figure 12. For the refined level 1-1 in Figure $12 \mathrm{a}$ ), the magnitude of force increases with the dielectric constant for $\mathrm{f}_{\mathrm{v}}=5 \mathrm{kHz}$ but decreases for $\mathrm{f}_{\mathrm{v}}=20 \mathrm{kHz}$. However this trend reverses in level 1-2 as in Figure 12 b), i.e. the magnitude of force increases faster for larger $f_{v}$. Similar trend is in the effect of $f_{v}$ with constant $\varepsilon_{d}$. The force generation decreases with larger $f_{v}$ in level 1-1, but although the frequency variation range is small, the magnitude of force increases with increasing frequency in level 
1-2 as in Figure 12 b). This effect is different from the other studies on frequency dependency on force generation. It has been reported that in a frequency range of several kilohertz order body force linearly increases with frequency ${ }^{18}$,

${ }^{36}$ or saturates at around $2 \mathrm{kHz}$ which is relatively low frequency ${ }^{14}$. Along with previously mentioned negative average force generation, it needs further study on the phenomena as well as development of current model.

The dependency of power on the dielectric constant and applied frequency is monotonic and it increases with increasing them, which is consistent with the experimental result ${ }^{16}$ although the average power used in this study does not accurately reflect the overall power input to the actuator.

\section{Summary and Conclusion}

Analysis on the parametric effect of the DBD actuator in helium is attempted by simulating the 2 species fluid model with the help of surrogate models. It has been found there are multiple Pareto fronts where parametric impacts and performance variables differ significantly. The degree of correlation and global sensitivity of design variables are much different in the low and high power regions. Averaged force and power show distinct difference in magnitude and/or direction. Surrogate models combined with detailed solution analysis help to understand correlated parametric dependency as summarized below.

\section{Dielectric constant}

It affects the amount of charged particle clouds above the insulator wall at the second half cycle. With a smaller constant, particle clouds thicken, increasing asymmetry in two half cycles. As a result $F_{x}$ increases. On the other hand it also affects the density of charged particle layer on the insulator surface. With a larger constant, higher electric field is induced, resulting in increase of $F_{x}$ in magnitude but to the negative direction. The amount of overall charged particle generation is also affected by this constant. With a larger constant, higher electric field and higher power input occur.

\section{Frequency of applied voltage}

It affects the amount of overall charged particle generation. With a higher frequency, less time of discharge is allowed and asymmetry in two half cycle decreases, resulting in increase of $F_{x}$ in magnitude but to the negative direction. Higher frequency accompanied by high dielectric constant induces higher power input.

\section{Positive-to-negative half cycle time ratio}

It also contributes to the amount of overall charged particles generation. With a larger constant, the first half cycle discharge becomes more prominent. As a result, $\mathrm{F}_{\mathrm{x}}$ increases. On the other hand, the amount of charged particle clouds above the insulator wall at the second half cycle is also influenced. The larger constant induces the smaller amount of particle, which means insufficient electric field for plateau region in the second half cycle. As a result $\mathrm{F}_{\mathrm{x}}$ decreases.

It is interesting to notice two Pareto fronts with different signs of $\mathrm{x}$-directional force. Each front is found to be in the region apart from the other in the design space we defined. This information can be used to enhance the performance of the actuator by informing effective control variables and their influence on the performance. However, the force generation and power consumption are also strong functions of other parameters such as electrode size, insulator thickness, and amplitude of voltage which are invariant in this study, and need to be considered.

Since the optimal conditions for the objective functions of force and power reside on the boundary of the design space, it is not feasible to decide on a global optimum at current time. It is widely reported that slight parametric changes can result in distinctly different discharge modes that can significantly alter force generation, power consumption and other performance goals. To increase the reliability of the analysis for practical purposes, as well as to find optimal conditions for a given parameter set, the fidelity of the numerical model needs to be assessed further.

\section{Acknowledgement}

The present work is supported by the AFRL, under a collaborative center agreement. 
${ }^{1}$ McDaniel, E. W., Collision Phenomena in Ionized Gases, John Wiley \& Sons, Inc., New York, 1964

2 Mitchner, M. and Kruger, C. H. Jr., Partially Ionized Gases, John Wiley \& Sons, Inc., New York, 1973

3 Boeuf, J. P., "Numerical model of rf glow discharges," Phys. Rev. A 36 (6), 1987, pp. 2782-2792

${ }^{4}$ Roth, J. R., and Sherman, D. M. "Boundary layer flow control with a one atmosphere uniform glow discharge surface plasma," AIAA Paper 98-0328, 1998

5 Shyy, W., Jayaraman, B., and Andersson, A., "Modeling of glow discharge-induced fluid dynamics," J. Appl. Phys., 92(11), 2002

6 Jayaraman, B., Cho, Y., and Shyy, W., "Modeling of dielectric barrier discharge plasma actuator," AIAA Paper 2007-4531, 38 $8^{\text {th }}$ AIAA Plasmadynamics and Lasers Conference, June 25-28, Miami, FL, 2007

7 Enloe, C. L., McLaughlin, T. E., VanDyken, R. D., Kachner, K. D., Jumper, E. J., and Corke, T. C., "Mechanisms and responses of a single dielectric barrier plasma actuator: plasma morphology," AIAA Journal Vol. 42, No. 3, March 2004, pp. 589-594

${ }^{8}$ Pons, J, Moreau, E. and Touchard, G., "Asymmetric surface dielectric barrier discharge in air at atmospheric pressure: electrical properties and induced airflow characteristics," J. Phys. D: Appl. Phys., Vol. 38, 2005, pp.3635-3642

9 Gherardi, N., and Massines, F., "Mechanisms controlling the transition from glow silent discharge to streamer discharge in nitrogen," IEEE Transactions on Plasma Science, Vol. 29, No. 3, June 2001, pp.536-544

${ }^{10}$ Roth, J. R., Industrial Plasma Engineering, Volume 2: applications to nonthermal plasma processing, IOP publishing, 2001

${ }^{11}$ Yuan, X., Shin, J., and Raja, L. L., "One-dimensional simulation of multi pulse phenomena in dielectric barrier atmospheric-pressure glow discharges," Vacuum 80, 2006, pp.1199-1205

${ }^{12}$ Porter, C. O., McLaughlin, T. E., Enloe, C. L., Font, G. I., Roney, J., and Baughn, J. W., "Boundary layer control using a DBD plasma actuator," AIAA Paper 2007-786, $45^{\text {th }}$ AIAA Aerospace Sciences Meeting and Exhibit, 8-11 January, Reno, NV, 2007

${ }^{13}$ Jukes, T. N., Choi, K, Johnson, G. A., and Scott, S. J., "Characterization of surface plasma-induced wall flows through velocity and temperature measurements," AIAA Journal, Vol. 44, No. 4, 2006, pp. 764-771

${ }^{14}$ Forte, M., Jolibois, J., Moreau, E., and Touchard, G., and Cazalens, M., "Optimization of a dielectric barrier discharge actuator by stationary and non-stationary measurements of the induced flow velocity - application to airflow control," AIAA Paper 2006-2863, $3{ }^{\text {rd }}$ AIAA Flow Control Conference, 5-8 June, San Francisco, CA, 2006

${ }^{15}$ Abe, T., Takizawa, Y., Sato, S., and Kimura, N., "A parametric experimental study for momentum transfer by plasma actuator," AIAA Paper 2007-187, 45 ${ }^{\text {th }}$ Aerospace Sciences Meeting and Exhibit, 8-11 January, Reno, NV, 2007

${ }^{16}$ Roth, J. R., and Dai, X., "Optimization of the aerodynamic plasma actuator as an electrohydrodynamic(EHD) electrical device," AIAA Paper 2006-1203, 44 ${ }^{\text {th }}$ AIAA Aerospace Sciences Meeting and Exhibit, 9-12 January, Reno, NV, 2006

${ }^{17}$ Gregory, J. W., Enloe, C. L., Font, G. I., and McLaughlin, T. E., "Force production mechanisms of a dielectricbarrier discharge plasma actuator," AIAA Paper 2007-185, 45 ${ }^{\text {th }}$ AIAA Aerospace Sciences Meeting and Exhibit, 8-11 January, Reno, NV, 2007

${ }^{18}$ Baughn, J. W., Porter, C. O., Peterson B. L., Mclaughlin, T. E., Enloe, C. L., Font, G. I., and Baird, C., "Momentum transfer for an aerodynamic plasma actuator with an imposed boundary layer," AIAA Paper 2006168, 44 ${ }^{\text {th }}$ AIAA Aerospace Sciences Meeting and Exhibit, 9-12 January, Reno, NV, 2006

${ }^{19}$ Boeuf, J. P., Lagmich, Y., Callegari, Th., and Pitchford, L. C., "EHD force in dielectric barrier discharges parametric study and influence of negative ions," AIAA Paper 2007-183, $45^{\text {th }}$ AIAA Aerospace Sciences Meeting and Exhibit, 8-11 January, Reno, NV, 2007

${ }^{20}$ Font, G. I., Enloe, C. L., McLaughlin, T. E., and Orlov, D., "Plasma discharge characteristics and experimentally determined boundary conditions for a plasma actuator," AIAA Paper 2007-188, $45^{\text {th }}$ AIAA Aerospace Sciences Meeting and Exhibit, 8-11 January, Reno, NV, 2007

${ }^{21}$ Likhanskii, A. V., Shneider, M. N., Macheret, S. O., and Miles, R. B., "Optimization of dielectric barrier discharge plasma actuators driven by repetitive nanosecond pulses," AIAA Paper 2007-633, $45^{\text {th }}$ AIAA Aerospace Sciences Meeting and Exhibit, 8-11 January, Reno, NV, 2007

${ }^{22}$ Roy, S., Singh, K. P., and Gaitonde, D. V., "Air plasma actuators for effective flow control," AIAA Paper 2007184, $45^{\text {th }}$ AIAA Aerospace Sciences Meeting and Exhibit, 8-11 January, Reno, NV, 2007

${ }^{23}$ Jayaraman, B., and Shyy, W., "Modeling of dielectric barrier discharge-induced fluid dynamics and heat transfer," Prog. Aero. Sci., doi: 10.1016/i.paerosci.2007.10.004, 2007 
${ }^{24}$ Visbal, M. R., Gaitonde, D. V., and Roy, S., "Control of transitional and turbulent flows using plasma-based actuators," AIAA Paper 2006-3230, 36 ${ }^{\text {th }}$ AIAA Fluid Dynamics Conference and Exhibit, 5-8 June, San Francisco, CA, 2006

${ }^{25}$ Jayaraman, B., Lian, Y., and Shyy, W., "Low-Reynolds number flow control using dielectric barrier discharge actuators," AIAA Paper 2007-3974, 37 ${ }^{\text {th }}$ AIAA Fluid Dynamics Conference and Exhibit, 25-28 June, Miami, FL, 2007

${ }^{26}$ Rizzetta, D. P., and Visbal, M. R., "Numerical investigation of plasma-based flow control for transitional highly loaded low-pressure turbine," AIAA Journal Vol. 45, No. 10, October 2007, pp.2554-2564

${ }^{27}$ Mack, Y., Goel, T., Shyy, W., Haftka, R., and Queipo, N., "Multiple surrogate for the shape optimization of bluff body-facilitated mixing," AIAA Paper 2005-333, $43^{\text {rd }}$ AIAA Aerospace Sciences Meeting and Exhibit, 10-13 January, Reno, NV, 2005

${ }^{28}$ Goel, T., Zhao, J., Tharkur, S., Haftka, R. T., and Shyy, W., "Surrogate model-based strategy for cryogenic cavitation model validation and sensitivity evaluation," AIAA Paper 2006-5047, 42 ${ }^{\text {nd }}$ AUAA/ASME/SAE/ASEE Joint Propulsion Conference \& Exhibit, 9-12 July, Sacramento, CA, 2006

${ }^{29}$ Goel, T., Haftka, R., T., Queipo, N., and Shyy, W., "Performance estimate and simultaneous application of multiple surrogates," AIAA Paper 2006-7047, $11^{\text {th }}$ AIAA/ISSMO Multidisciplinary Analysis and Optimization Conference, 6-8 September, Portsmouth, VA, 2006

${ }^{30}$ Jayaraman, B., Tharkur, S., and Shyy, W., "Modeling of fluid dynamics and heat transfer induced by dielectric barrier plasma actuator," J. Heat Trans., Vol. 129, April 2007, pp. 517-525

${ }^{31}$ Ward, A. L., "Calculations of cathode-fall characteristics," J. Appl. Phys., 33(9), 1962

${ }^{32}$ Jayaraman, B., Cho, Y., and Shyy, W., "Modeling of dielectric barrier discharge plasma actuator," Submitted to J. Appl. Phys., 2007

${ }^{33}$ Morrow, R, and Sato, N. "The discharge current induced by the motion of charged particles in time-dependent electric fields; Sato's equation extended," J. Phys. D: Appl. Phys., Vol. 32, L20-L22, 1999

${ }^{34}$ Myers, R. H., and Montgomery, D. C., Response Surface Methodology: Process and Product Optimization Using Designed Experiments, $2^{\text {nd }}$ ed., John Wiley \& Sons, Inc., 2002

${ }^{35}$ Singh, K. P. and Roy, S., "Modeling plasma actuators with air chemistry for effective flow control," J. Appl. Phys., 101(12), 2007

${ }^{36}$ Porter, C. O. Baughn, J. W., McLaughlin, T. E., Enloe, C. L., and Font, G. I., "Plasma Actuator Force Measurements," AIAA Journal Vol. 45, No. 7, July 2007, pp. 1562-1570 